\title{
Competitive universities need to internationalize learning: Perspectives from three European universities
}

\author{
Ana Maria Lara ${ }^{1}$; Keith Stuart ${ }^{2}$; Jan Karpe ${ }^{3}$; Heide Faeskorn-Woyke ${ }^{3}$; \\ Raúl Poler ${ }^{2}$ Rafael Brotons ${ }^{4}$ \\ ${ }^{1}$ University of Burgos (SPAIN); ${ }^{2}$ University of V alencia (SPAIN); \\ ${ }^{3}$ University of Applied Sciences Cologne (GERMANY); ${ }^{4}$ Grupo Antolin S.A. (SPAIN) \\ amlara@ubu.es; kstuar@@idm.upv.es; karpe@gm.fh-koeln.de; faeskorn@gm.fh-koeln.de; \\ rpoler@,omp.upv.es; rabrocano@,botmail.com
}

Received October 2008

Accepted May 2009

\begin{abstract}
The process of restructuring European universities in order to harmonize their educational systems is rapidly approaching a key milestone as 2010 looms large on the horizon. This paper describes an approach to the European Higher Education Area (EHEA) based on a real case study of students that belong to five European Universities (University of Burgos, Technical University of Valencia, University of Valladolid, University of Basque Country and University of Applied Sciences Cologne). The objective of this paper is two-fold: on the one hand, to analyze from the student's point of view how they value the restructuring of teaching as a result of the Bologna process and what are the implications for students with regards to both their academic qualifications and their future incorporation into the labour market; and, on the other hand, to deduce from the results obtained recommendations which may help to guide teachers towards successful internationalization and collaboration between interuniversity networks, as well as achieving greater standards of quality within university teaching. Only this would permit an environment in which students are capable of developing the necessary competences, and put into practice learning outcomes.
\end{abstract}

The results show that students value communication, innovative proposals and cooperation between universities; the internationalization of knowledge between 
universities has been positively accepted and this has motivated research to place a stronger focus on this aspect; it impacts strongly on scientific productivity, improves the quality of education offered by the teaching staff, and leads to greater student mobility. This strategy is intrinsically linked to learning from local experiences shared by members of the same university as well as from more global experiences made available through inter-university networks. It implies being willing to listen, to communicate, to engage in dialogue and means that we must seek to understand the potential contributions from teachers, staff and students that make up each university.

Keywords: bologna process, european higher education, competitive universities, internationalisation

\section{Practical implications of the European Higher Education Area in universities}

Lengthy conversations between university teaching staff about the European Higher Education Area (EHEA) and the future of management, teaching and research within universities to be introduced by 2010 are now a thing of the past. The EHEA is a reality that now must be taken on board; no time is left for philosophizing, reticence or insecurity. Improvements to the quality of our university teaching and research represent the most stable objective and, with that, improvements to everything else within the system: its structure, its management, teaching resources and research, among others. The time has come to transfer university knowledge beyond national and linguistic boundaries; without a doubt, the accreditation of qualifications contributes to this goal, as do study periods abroad, opening up extra-communitarian frontiers, employment opportunities in foreign firms, collaborative projects and research through European inter-university networks. In order to move towards these goals, greater commitment is called for and greater personal effort must be made than has been the case up until now. Specific training for teaching staff, and learning from common experiences between members of the same university and those from other universities will be needed, as well as a strong will to listen, communicate, exchange viewpoints and a desire to understand what each person can contribute. 
These actions are implicitly or explicitly laid out in the planned objectives for the EHEA (European Area of Higher Education); the Council of Ministers for Education (2008) summarised the Bologna Process objectives and incorporated agreements made in Bologna, Prague and Berlin between 1999 and 2003:

- Adoption of a system of easily readable and comparable degrees.

- Adoption of a system essentially based on two main cycles (bachelors and masters).

- Establishment of a system of credits - such as ECTS.

- Promotion of mobility for students, academic and administrative staff.

- Promotion of European cooperation in quality assurance.

- Promotion of the European dimension in Higher Education.

- Lifelong Learning.

- Promoting the attractiveness of the European Higher Education Area in a global setting.

- Doctoral studies and the synergy between the European Higher Education Area and the European Research Area.

Given that this paper has focused its analysis on the role of the student, as the recipient partner of the new educational reform, and how from the results obtained this reform contributes to establish, according to the fundamental principles of Bologna, a system of greater teaching quality through internationalization, and more particularly in Computer Science and Engineering Faculties, it is necessary to analyze how accreditation organisms and associations have planned these proposals.

The European Association for Quality Assurance in Higher Education (ENQA) (2006) has also focused on the role of students saying "they have a special interest in factors that are relevant in making education a good investment. Students should be seen as partners in the academic community, because they often have a balanced view of the aim of the academic institution; on the cultural, political and 
historical aspects of the academic community; on the institutions' role in society and on the future of the academic tradition. This insight combined with factors such as the influence of their age, their peer group, and the time they live in, means that students may bring a valuable perspective into the panel's work".

ANECA (National Agency for Quality Assessment and Accreditation) (2004) in its EICE Project (Estudios de Informática y Convergencia Europea) has developed the White Paper on University Computer Science Qualifications in the new European Higher Education Area and justifies this argument applicable to other areas of engineering by affirming that "in the specific case of computer science studies, internationalization is fundamental, not only because of the possible demand on the part of foreign students, but also because of the nature of the studies, as the knowledge to be learnt is of an intrinsically international nature, as the technology in general and especially ICT constitute a field of knowledge that is less dependent on local or regional characteristics, in which the advances are applied in a very similar way across the world regardless of where they originate".

This European and international dimension of dismantling frontiers and the generalisation of knowledge is also noted in the Declaration of Graz (2003) when it speaks about the role of universities stating that "the development of European universities is based on a set of core values: equity and access; research and scholarship in all disciplines as an integral part of higher education; high academic quality; cultural and linguistic diversity".

Engineering qualifications are likely to be improved through the use of the most modern technology, the most innovative concepts and the experience of the most versatile experts.

\section{Situational analysis of the state of engineering qualifications since the beginning of internationalization}

The pace at which universities have integrated different proposals - since the first meeting held in Prague, in May 2001- into their educational activities has been constant. The participant universities have come a long way in this sense, given their participation in EICE, as well as in another fifteen such projects. However, a lot of work remains to be done and difficulties to be overcome given the varied list of points that are covered in the Declaration of Bologna. 
The very fact of wishing to examine such improvements in greater depth and to bring in significant and essential changes, which at the same time are enriching for these universities, are cause enough to justify wishing to continue with research through pilot projects. Improvements in the quality of teaching amounts to making the educational system more enriching, taking care that the acquisition, transference and updating of learning and knowledge -between European universities, which implies internationalization- is the most representative key factor; a point underlined within the Bologna process.

The European University Association (EUA) (2005) also make this clear in their report about putting into practice the Bologna process in European universities, where they highlight that "the added values which institutions associated with the Bologna reforms cover quite a wide spectrum of issues, revealing a wide variety of reasons for integrating Bologna reforms into institutional strategic plans. (...) some institutions expect that internationalization and the mobility of their institution to be furthered by the reforms".

The EHEA sets out as a general priority objective the "promotion of European cooperation in quality assurance with a view to developing comparable criteria and methods". More particularly, one of the recommendations of the European Parliament and Council on greater European cooperation for quality assurance in higher education, in a meeting held on 15th February 2006 calls for “(...) quality assurance systems to be based on a series of essential features, including evaluation of programmes or institutions through internal assessment, external review, and involving the participation of students, publication of results and international participation." (Recommendation 98/561/EC of the European parliament and of the council of 15 February 2006 on further European cooperation in quality assurance in higher education (2006/143/EC) (last accessed 25/04/08).

Another aspect that bears relation to the importance of internationalization to universities is picked up in a study by the Academic Cooperation Association (ACA) in that it is emphasized that to internationalize is to generate cognitive wealth. The authors, Kelo and Wächter (2004) call this brain circulation or brain mobility. To internationalize is a synonym for "creating bridges which contribute to a transfer of technology and knowledge back to their country of origin". 
Without a doubt, accreditation is the barometer of the standards reached in quality. In this way and since in this paper engineering disciplines are being considered, the Accreditation Agency for Degree Programs in Engineering (ASIIN) (2004) emphasizes in their article on the requirements and principles for the accomplishment of accreditations in engineering studies and computer science with regards to bachelor and masters the fact that "the offer of studies, to be considered that is going to be the object of an accreditation, must have a demand of people interested in those studies, a necessity in the medium and long term on the part of the labour market and work possibilities for the students of these studies that are going to be accredited. For this reason, one should not forget the process of internationalization that may lead to accreditation".

Due to the importance of internationalization, quality in engineering education undoubtedly demands that we set out to achieve the following objectives:

- Changes in the teaching methods used up until now.

- Offer and assessment of the number of credits that may be taught on bilingual courses.

- Follow up of the necessary changes.

- Ongoing review of the feasibility of costs and investments for equipment (taking into account that information technology and software tools are the most appropriate in computer science).

- Refresher courses (for teaching staff).

- Assessment of teaching staff.

- Assessment of student satisfaction.

- Level of theoretical knowledge and practical application of the course material studied, that is to say, level of acquisition of competences.

- Ensure quality standards for teaching. This should relate to learning outcomes. 
- Monitoring of the core activities of accreditation "whose emphasis is placed on supporting university administration in internal quality management" (Comet, De la Rosa, Fischer, Ploug \& Ponds, 2008).

- A search for determining factors that create links to the external world and the employment market, in order to know how to orient students throughout their academic courses.

- The degree of technological specialization that is taught in the material (use of new software according to each area).

- The scientific level of the teachers that provide information and knowledge (professionals that know how to communicate information on advanced applications that is based on research experience -congresses, publications in indexed reviews, national and international conferences, regional, national and European projects-).

- The professional profile of the students. It is considered to be very important to know how the material should be adapted and focused to establish a balance between course contents and each student's future professional skills.

Important work must be done in universities, in view of the improvements now underway, and more specifically for those oriented towards the internationalization of teaching. The offer of subjects taught in English is one of the aspects that is explicitly covered in the European Supplement to the Qualification. Not only does it enrich the teaching staff (improving the teaching experience of whoever gives the course) and the students (facilitating their preparation for and entry into the world of work), but it also adds value to the university (the offer of bilingual subjects can be a reason to attract more Erasmus students and to gain prestige and image beyond national frontiers).

Thus, collaboration with other universities that are further down the road is necessary. The network set up for this project allows us to share and to engage in dialogue with teachers from other centres on how they have managed to establish agreements and rules in matters concerning bilingual teaching from the viewpoints of an Area, a Department or a Vice-rectorate. It may be seen from the study that is analysed in this paper that in engineering qualifications another factor of some 
weight also exists, which is that a high percentage of the students are already immersed in paid employment, combining their studies in higher education with activities in companies. This means that the priority objective is to know whether the overall focus given to the subjects that are being taught is at the correct level for these universities and these students. High academic quality and more practical orientations in relation to the social and professional values of this collective make it necessary once again to set out the following objectives:

- To study the strategy for implementing bilingual teaching in their subject modules.

- To seek out competent teaching staff for each subject area, not only in educational terms, but of course in terms of research and professional experience.

- To know how to focus subject matter that is taught in accordance with the needs of the market and to ensure that within a short period of time the student will know how to develop. In short, to prepare our students fully and completely concentrating on their professional skills.

In order to be able to carry out all these initiatives, it is necessary to discover the position of students within this new context and what they think about the new challenges being presented to them; the study that was carried out and the research methodology is presented in the following section.

\section{Field-work methodology. Structure of the questionnaire}

This study has its origins at the University of Burgos within the project UBU14/07. Its justification is due to the problem caused by the reduction in the numbers of students registering in the Masters Degree of Computer Science Engineering over the last few years. At the University of Burgos, Computer Science Engineering first began to enroll students during the academic year 2001-2002. It is a Masters degree and 41 students registered. Throughout the last few years, the demand to enroll in this Masters degree and the number of graduates has been constant but not very numerous. In order to be able to contain and even to increase the numbers, it is in large measure a major teaching and research effort that is required in educational matters and individual subjects as well as a positive 
implementation of the objectives established by the EHEA. The joint work of these five universities has been decisive in order to be able to assess the student environment in these engineering disciplines and to successfully obtain a package of excellent information as far as student needs, insecurities and criteria. In figure 1 , we show the record of enrollment in the University of Burgos as an example of the case study analyzed here.

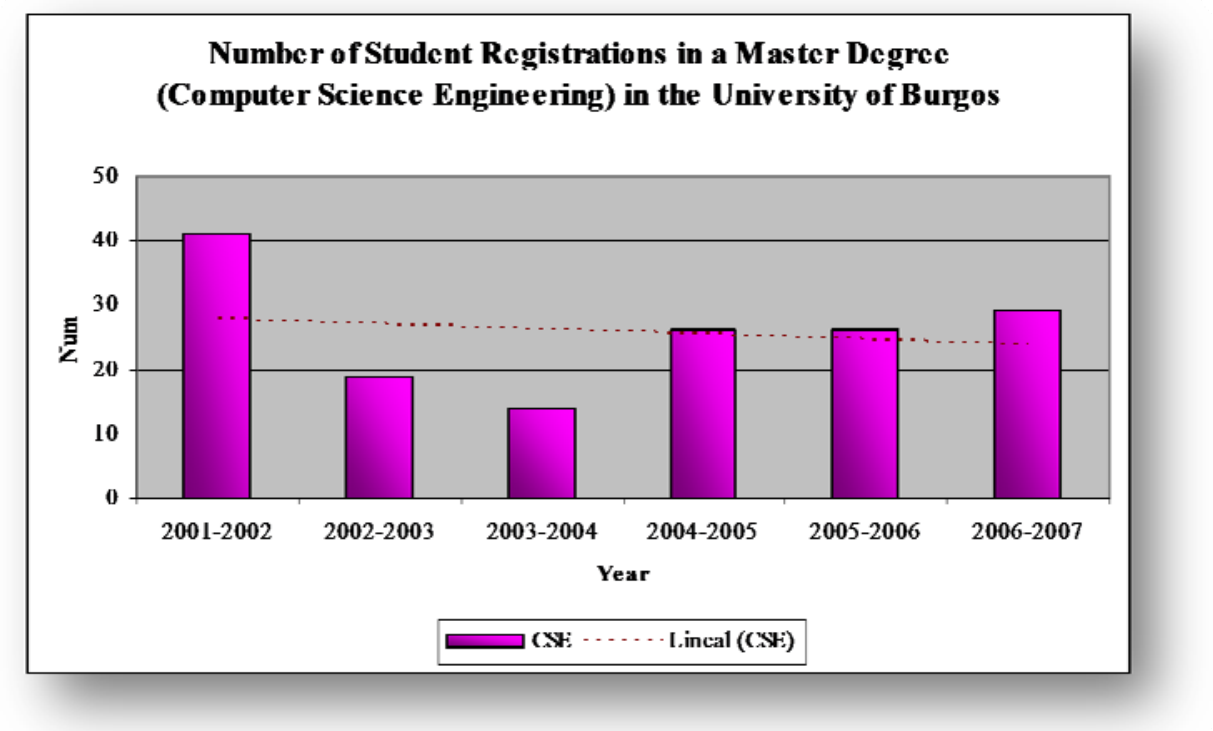

Figure 1. "Number of Registrations in Master Degree in the University of Burgos (Computer Science Engineering)". Source: Own contribution

Having set out the critical points which have to be targeted, a questionnaire was drawn up for students. The design of the questionnaire for students has been developed considering general and particular aspects of the new learning environment:

- Students' personal data and academic profiles (it is considered important to know, among other things, if the student works and studies at the same time and if he is attending a degree course for the first or second time).

- Opinions on the contents of the new restructuring in the EHEA (in order to be able to undertake changes without generating mistrust, it is important that students are familiar with the objectives that are formulated in the Bologna process. For this reason, it is considered important to find out if the student knows and has evaluated the changes critically, if the student sees 
as important the recognition of degrees, and how they would improve the new system of education, etc.).

- Changes which relate to assessment methods and the assessment of their academic results (it is considered important to know, among other things, how the student perceives the importance of the ability to work, leadership and innovation and what stands out as being necessary and urgent to improve: technical knowledge acquisition, group work, initiative, capacity for learning or creativity).

- The importance of languages (in order to foment internationalization, the participation of students is something fundamental; for that reason it is good to knowing how many languages students speak, if they have participated or they would like to participate in an ERASMUS program, if they consider mobility as one of the defining characteristics for their professional future, etc.)

- The students' professional future (how to get access to the labour market continues to be a constant question for students; for this reason, it is necessary to find out the opinion of students about this aspect after Bologna. Are languages, their academic profile, the most important aptitudes now? Some of these answers reflect their real perception and how they intuit the labour market will be in the future).

- The degree of preparation that they have observed in the teaching staff in the face of these planned changes to university teaching (the perception of the student on the traditional preparation of the teaching staff, classes, classroom interaction or their commitment in tutorial sessions contributes information about what the profile of the new teaching staff should be after Bologna from a student's perspective).

In total, 40 questions were distributed among the above-mentioned sections. It should be added that the study was only directed at Computer Science students and the sample of students that responded to the questionnaire numbered 447 . In table 1 are the data of the sample chosen in relation to the total population. For the calculation of reliability, standard error estimation has been chosen (Lininger y Warwick, 1985). 


$$
S E E=\sqrt{\frac{N-n}{N}} \sqrt{\frac{1}{n}}
$$

Equation 1. "Standard Error Estimation”. Source: Lininger \& Warwick, 1985

The rigour with which the data has been treated, has allowed us to consider that the chosen sample is representative of the total population, since a reliability of $85.53 \%$ is reached in the University of Burgos; $95,15 \%$ in the University of Valladolid; $92,18 \%$ in the Technical University of Valencia; $95,54 \%$ in the University of Bilbao and $94,39 \%$ in the University of Applied Sciences of Cologne.

The information in the questionnaires was stored in a database designed for this study. Statistical treatment of the information was carried out using QAnalysis software which was used to obtain the initial results, which immediately led to reflections on the strengths, weaknesses, threats and opportunities available to each university. The preparation of the questionnaire and the collecting of data was carried out over the months of November and December 2007, and January and February 2008, respectively. Data treatment took place in March and April 2008. The following section shows the graphs generated from the data and their most interesting and striking considerations.

\begin{tabular}{|c|c|c|}
\hline \multicolumn{3}{|c|}{$\begin{array}{c}\text { SAMPLE CHOSEN } \\
\text { (Students in Engineering Computer Science) } \\
\text { AND REALI ABI LI TY REACHED (total population) }\end{array}$} \\
\hline \multicolumn{3}{|l|}{ SAMPLE } \\
\hline University & Value-Sample & $\%$ \\
\hline University of Burgos & 76 & $17 \%$ \\
\hline University of Valladolid & 126 & $28 \%$ \\
\hline Technical University of Valencia & 40 & $9 \%$ \\
\hline University of Bilbao & 126 & $28 \%$ \\
\hline University of Applied Sciences Cologne & 79 & $18 \%$ \\
\hline TOTAL & 447 & $100 \%$ \\
\hline \multicolumn{3}{|c|}{ TOTAL POPULATION } \\
\hline University & \multicolumn{2}{|c|}{ Realiability Reached (\%) } \\
\hline University of Burgos & \multicolumn{2}{|c|}{$97,76 \%$} \\
\hline University of Valladolid & \multicolumn{2}{|c|}{$95,15 \%$} \\
\hline Technical University of Valencia & \multicolumn{2}{|c|}{$92,18 \%$} \\
\hline University of Bilbao & \multicolumn{2}{|c|}{$95,54 \%$} \\
\hline University of Applied Sciences Cologne & \multicolumn{2}{|c|}{$94,39 \%$} \\
\hline
\end{tabular}

Table 1. "Realiability Reached in every university. Academic Year 07-08". Source: Own contribution 


\section{Mathematical simulation, results and implications}

Using the database designed to collect the 447 questionnaires, work proceeded with the Q-Analysis mathematical software tool to simulate the results and the subsequent graphs that are briefly commented on below.

In order to carry out a correct interpretation of the results, it is necessary to indicate the percentages of polled population in each one of the member universities (University of Applied Sciences Cologne (KOLN), University of Burgos (UBU), University of Basque Country (UPV), Technical University of Valencia (UPVLC), and University of Valladolid (UVA). Figure 2 shows the results to all questions of each section. In order to be more efficient, the table of results is in the annexe of the paper.

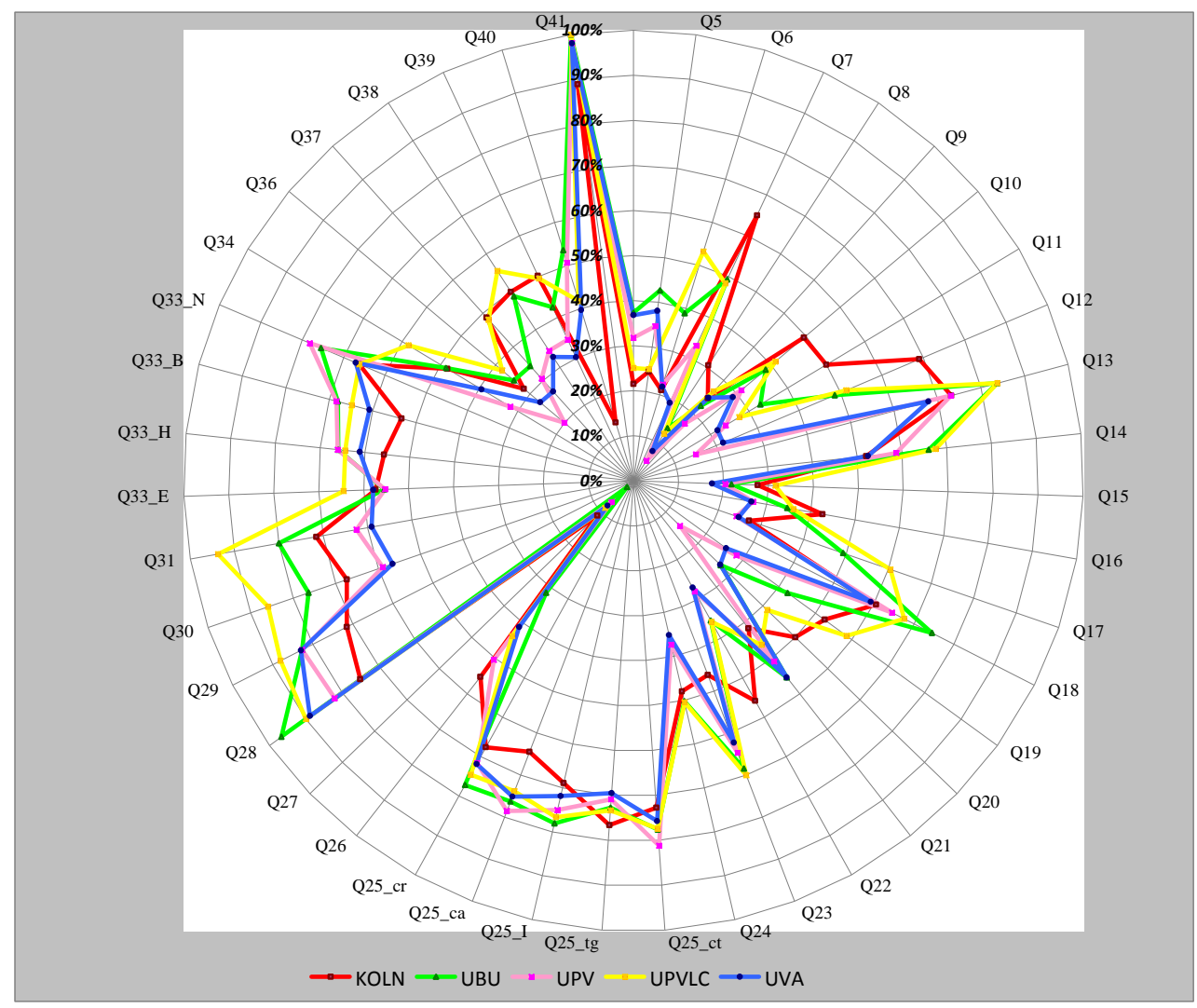

Figure 2. "Q-Analysis Database Results". Source: Own contribution

The initial evaluation of the results is satisfactory -the general viewpoint is one that welcomes the programme and expresses confidence in it, even though rather disappointing percentages may appear in some cases-, and deserves to be 
analysed in the case of the most significant questions and as helpful lessons and examples in our universities. According to the different results of each section of figure 2, we can establish some points of reflection:

- According to section 1, about the person, a very high percentage of the population under analysis is working while studying. This fact leaves a profound question mark as to the appropriateness of readapting university courses for 2010 by introducing a more practical component. Students learn to distribute their time, to prioritize their commitments and it generates a working discipline that is very similar to what their future integration in the job market will entail.

- According to section 2, About the contents of the EHEA, around three quarters have no notion of the Bologna Process or the changes that it could mean for their qualifications. This fact is once again clearly highlighted, as this same percentage is repeated among students that say they have not participated in either meetings or committees on the Process. Undoubtedly these statements on being disconnected with the Process may justify certain rather indecisive results. The conclusions that may be drawn from all this is to take full advantage of this period of two years up until its definitive implementation in order to include the presence of rather more students in the working sessions that there are at present. There is a great wealth in their appraisals that may be of help both to administrators and to the teachers themselves.

- Section 3, About the students assessment methods, the most significant point is related to the standardization of accreditations; it is widely recognized by a great majority - three quarters- as a definitive step towards the creation of new and more potent structures for integration. The employment market is thereby presented as being closer and as offering greater opportunities. A priori, the enormous effort to adapt aptitude and abilities to the external world should be brought to a conclusion, given that the same assessment system will be used for everybody. In this specific case, it is made more obvious given that $74 \%$ of interviewees speak two of three languages and $7 \%$ more than three, which is really positive and beneficial. 
- Internationalization, considered in section 4, About the importance of languages, only a minority have followed an academic course abroad. As argued in the Bologna Process, it is everybody's desire that all the universities offer a greater number of places for both students and teachers to enlarge their store of experiences and knowledge. There is not the slightest doubt that universities cooperating as academic structures will also grow and become stronger building on their reputation and merits. As a consequence, it is essential that each and every member of staff cooperating in this Project takes on board the urgent need to introduce bilingual education into Spanish universities, in such a way that it will be less taxing on students to summon up the will to study abroad either at the end of their academic studies or when they embark on their professional career.

This is the initial starting point in order to eliminate the psychological, social, personal and academic barriers that a student faces when considering whether to apply for a study period abroad. The will is there but only a few have taken the first step. Since languages are one of the pillars to achieve internationalization, this is reflected in table 2 ordered by countries and by universities giving the resulting percentage for each question of this section. To put a simple example, it is possible to compare Germany in relation to Spain and we find that German students have a far better level as far as the number of languages that are spoken by students and greater participation in ERASMUS mobility programs.

Students from both countries think that with Bologna it will be simpler to study abroad. Nevertheless, Spanish students consider that studying abroad is really important. If an analysis is carried out among Spanish universities, the Technical University of Valencia and the University of Valladolid head the list of universities with greater participation in ERASMUS mobility programs, they are followed by the University of the Basque Country, and finally, the University of Burgos is the one that worse results obtains. 


\begin{tabular}{|l|l|l|l|l|l|l|l|l|l|l|l|l|l|}
\hline PERCENT & & Q26 & Q27 & Q28 & Q29 & Q30 & Q31 & Q33_E & Q33_H & Q33_B & Q33_N \\
\hline TOTAL & T & $45 \%$ & $7 \%$ & $86 \%$ & $81 \%$ & $65 \%$ & $70 \%$ & $57 \%$ & $63 \%$ & $63 \%$ & $71 \%$ \\
\hline \multirow{2}{*}{ Country } & ES & $43 \%$ & $6 \%$ & $88 \%$ & $83 \%$ & $65 \%$ & $69 \%$ & $57 \%$ & $64 \%$ & $65 \%$ & $72 \%$ \\
\hline & GER & $55 \%$ & $11 \%$ & $75 \%$ & $71 \%$ & $67 \%$ & $72 \%$ & $57 \%$ & $56 \%$ & $53 \%$ & $66 \%$ \\
\hline \multirow{3}{*}{ University } & KOLN & $55 \%$ & $11 \%$ & $75 \%$ & $71 \%$ & $67 \%$ & $72 \%$ & $57 \%$ & $56 \%$ & $53 \%$ & $66 \%$ \\
\hline & UBU & $32 \%$ & $2 \%$ & $97 \%$ & $83 \%$ & $76 \%$ & $80 \%$ & $55 \%$ & $66 \%$ & $68 \%$ & $75 \%$ \\
\hline & UPV & $50 \%$ & $7 \%$ & $82 \%$ & $83 \%$ & $59 \%$ & $63 \%$ & $55 \%$ & $66 \%$ & $68 \%$ & $78 \%$ \\
\hline & UPVLC & $44 \%$ & $9 \%$ & $90 \%$ & $88 \%$ & $86 \%$ & $94 \%$ & $65 \%$ & $64 \%$ & $65 \%$ & $66 \%$ \\
\hline
\end{tabular}

Table 2. "Q-Analysis Database". Source: Own contribution

- Should motivation be an aspect to consider in this initiative in order to achieve a more committed approach from students towards their own personal effort, and towards their university learning process? Only a mere $2 \%$ consider that the new change will be motivating. There are more and more external agents that disrupt their concentration and the will to work of our students, and perhaps a call should be made to reconsider how we may change these circumstances in universities. Nothing is attained without effort and it is right to strive for what is really of concern to the teacher, which is the quality of the student's education. Using motivating and attractive tools should also form part of the material used in each class and with each person.

Thus, bilingual classes are also proposed as a means to achieve improvements on this point. This could be a reflection for teachers in order to be more competitive in the learning process. Section 5, About the teachers provide us the following information: three quarters of the interviewees consider that the teaching staff is not prepared to confront the changes. Moving from the traditional to the innovative teaching structures as proposed in the Bologna Process might at first result somewhat complex. This point may be overcome by understanding that -without losing the fundamental role of the teacher as the source of the knowledge that is transferred-, the teaching staff must make their teaching more participative. The personal work load, the enlargement of tutorial times, the assessment of group work and creativity assume greater weight than concise technical knowledge. This is also reflected in the order of importance given by the students themselves. These days, teachers must pause to reflect on their working methods seeking to harmonize understanding of basic subject 
descriptors and content with the use of more personalized systems of assessment. Therefore, it might be of some importance the proposal to establish standards of quality to assess teaching staff en-masse. In recent years, many teachers have invested time in training, their textbooks or teaching innovations.

- Finally, according to section 6, About professional life, the paradigm of entry to the employment market is both a concern and an aspiration for students. The result of many years of effort and dreams of a prosperous future professional life become tangible when students manage to gain employment in accordance with the studies they have followed. On this point, it is also imperative to assess the quality of each university's actions that will be carried out under the Bologna process, which bears witness to the great hope invested both by students and by teachers in the future.

The analysis highlights the urgency of having an adequate system of higher education in our universities to guide students, maintain their motivation and achieve learning outcomes and, thus, ensure the success of our universities as institutions of that are more than teaching, but where learning happens.

\section{Concluding remarks}

The paper describes a student point of view of the Bologna process within the framework of the EHEA. From the results obtained, we can deduce that there are some key elements to reach quality standards in a university and it is to be understood that the internationalization of learning is one of the most important factors and on which there is a need to make a greater emphasis. Promotion of mobility for students, teachers and administrative staff, investigation through interuniversity networks and the exchange of knowledge transforms traditional educational systems into new models that will lead the universities of the future.

The findings suggest that it is essential to orient training and learning towards educational tools that allow students to acquire competences that in the future they will have to make use of in their jobs.

As the European University Association (EUA) (2006) states, "language, cultural issues and knowledge of the educational system in foreign countries present true 
challenges to the involvement of students. This of course sets an additional requirement for students' competences, as it does for the panel as a whole. (...) Despite their potentially varying perspectives, the expert panel members all have the same goal: a system where the higher education institutions function at their best; and a versatile, flexible system with better learning conditions, including the wellbeing of staff. The creation of better learning outcomes is the overall goal of evaluation".

The main idea behind the developed framework is not to draw up a league table of universities but to take stock of the situation and generate continuous improvements each serving as mutually supportive examples for the strong points and for changing what is not beneficial. The need may be discerned, from all of these remarks, to internationalize our teaching methods and the education of our students. It is reasonable to conclude that the future does not lie in a greater amount of material but in better quality teaching and explanations. The paper, therefore, provides among other recommendations that internationalization allows us to add new life to the traditional university structures, new and enriching ways of functioning and a widely recognised vision of the need to plan the extracommunitarian university area.

\section{Acknowledgments}

These recommendations formed the backdrop to the search for an interdisciplinary team of university members whose investigative work has led to the conclusions contained in this paper This work is the result of a research project funded by the Consejería de Educación (Junta de Castilla y León) under reference UBU14/07, entitled “La Transferencia del Conocimiento Universitario más allá de los Límites I diomáticos: Implantación de la Docencia Bilingüe en las Titulaciones de Ingeniería Informática e Ingeniería de Organización Industrial de la Universidad de Burgos, como Antesala del Proceso de Bolonia [The Transference of University Knowledge Beyond Linguistic Constraints: the Introduction of Bilingual Teaching into Computer Science Engineering and Industrial Engineering Qualifications at the University of Burgos, as a Prelude to the Bologna Process]". Also the paper has been supported by the Ministerio de Educacion y Ciencia, trough Programa Nacional de Movilidad de Recursos Humanos del Plan Nacional de I+D+i 2008-2011. 


\section{References}

Alaniska, H., Arboix, E., Bohrer, J., Dearlove, R., Eriksson, S., Helle, E., \& Wiberg, L. (2006) in ENQA (European Association for Quality Assurance in Higher Education). Student involvement in the processes of quality assurance agencies. Helsinki.

ANECA (National Agency for Quality Assessment and Accreditation) (2004). EICE Project (White Paper on University Computer Science Qualifications in the new European Higher Education Area).

ASIIN (Accreditation Agency for Degree Programmes in Engineering) (2004). Requisitos y principios para la realización de acreditaciones de estudios de ingeniería e informática a nivel de bachelor y máster.

Boyd, F., \& Diener-West, M. (2006). Methods of learning in statistical education: a randomized trial of public health graduate students. Statistics Education Research Journal, 5, 19.

Casanovas, J., Colom, J. M., \& Morlán, I. (2004). Libro Blanco sobre las titulaciones universitarias de informática en el nuevo espacio europeo de educación superior. ANECA. Los estudios de Informática y la Convergencia Europea. Proyecto EICE: Ingeniería en Informática.

Comet, N., De la Rosa, C., Fischer, F. P., Ploug, S. \& Ponds, H. (2008). Internal quality assurance and the European Standards and Guidelines. European Association for Quality Assurance.

Committee of Postsecondary ADMs (PSADM) (2008). European Higher Education Area (EHEA). The Bologna Process. Council of Ministers of Education, Canada.

European University Association (EUA) (2007). Creativity in Higher Education. Report on the EUA Creativity Project 2006-2007.

European University Association (EUA) (2003). Forward from Berlin. The role of the universities. Graz Declaration.

Mundet, J., \& Sallán, J. M. (1995, May). La innovación en el proceso estratégico: una aproximación al estudio del comportamiento estratégico de las universidades 
catalanas. Paper presented at the meeting of the $\mathrm{V}$ Congreso Hispano-Francés, Toledo (Spain).

Hinojo, F. C. (2006). Leadership and the European Higher Education Area (EHEA). International J ournal of Learning, 12(1), 147-154.

Huisman, J., \& Van der Wende, M. (2005). On Cooperation and Competition II. Institutional Responses to Internationalisation, Europeanization and Globalisation. ACA Papers on International Cooperation in Education at a glance. Bonn, Lemmens.

Karpe, J. (1996). Rationalität und mentale Modelle. Europäische Hochschulschriften, Reihe V: Volks- und Betriebswirtschaft. Berlin, Bern, Frankfurt/Main, New York, Paris, Wien (Book, 343 Pages).

Kelo, M. (2006). Support for International Students in Higher Education. ACA Papers on International Cooperation in Education at a glance. Bonn, Lemmens.

Kelo, M., Teichler, U., \& Wächter, B. (2006). Student mobility in European higher education. ACA Papers on International Cooperation in Education at a glance. Bonn, Lemmens.

Kelo, M., \& Wächter, B. (2004). Brain Drain and Brain Gain. Migration in the European Union after enlargement. ACA Papers on International Cooperation in Education at a glance. Bonn, Lemmens.

Le Gallo, M., \& Dallerba, M. (2004). Evaluating the Temporal and the Spatial Heterogeneity of the European Convergence Process, 1980-1999. Paper presented in Working Papers of GRES-Cahiers du GRES 2004-23, Groupement de Recherches Economiques et Sociales.

Leggett, B., Harvey, M., \& Leng, H. (2007). Opening up thinking: reflections on group work in a bilingual postgraduate program. International J ournal of Teaching and Learning in Higher Education. 19(2), 105-116.

Lininger, Ch., \& Warwick, D. (1985). La encuesta por muestreo: teoría y práctica. CECSA. México. 
Reichert, S., \& Tauch, C. (2005). Universidades Europeas. Puesta en práctica de Bolonia. EUA (European University Association).

Wächter, F., \& Maiworm, B. (2008). English-Taught Programmes in European Higher Education. The Picture in 2007. ACA Papers on International Cooperation in Education at a glance. Bonn, LeCites in text.

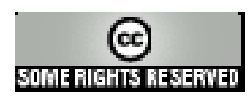

Article's contents are provided on a Attribution-Non Commercial 3.0 Creative Commons License. Readers are allowed to copy, distribute and communicate article's contents, provided the author's and Journal of Industrial Engineering and Management's names are included. It must not be used for commercial purposes. To see the complete license contents, please visit http://creativecommons.org/licenses/by-nc/3.0/ 